fournal of Medical Genetics (1976). 13, 366-370.

\title{
Partial monosomy and partial trisomy 18 in two offspring of carrier of pericentric inversion of chromosome 18
}

\author{
ANGELA M. VIANNA-MORGANTE, MARIA JOSE NOZAKI, CLÁUDIO C. ORTEGA, \\ VERÔNICA COATES, and YSAO YAMAMURA
}

\author{
From the Laboratório de Genética Humana, Departamento de Biologia, Instituto de Biociências, Universidade de \\ São Paulo; Departamento de Pediatria e Puericultura, Faculdade de Medicina da Santa Casa, São Paulo; \\ Centro de Habilitação da APAE, São Paulo; and Escola Paulista de Medicina, São Paulo, Brazil
}

Summary. A pericentric inversion of chromosome 18 is described in the mother of a patient with clinical diagnosis of $18 \mathrm{q}$ - syndrome. The propositus' chromosome complement includes the recombinant 18 with deficiency of the distal one-third of the long arm and duplication of the terminal segment of the short arm. The propositus' sister carries the recombinant 18 with a duplication of the distal one-third of the long arm and a deficiency of the terminal segment of the short arm. The relative length of the inverted segment represents about $60 \%$ of the total chromosome 18 length. The probability of recombinant formation following the occurrence of a chiasma within the inverted segment is predicted to be high.

In humans, familial pericentric inversions of autosomes have been found both in patients with multiple congenital anomalies caused by chromosome deficiency and duplication (Wilson et al, 1970; Parrington and Edwards, 1971; Faed et al, 1972; Hauksdöttir et al, 1972; Morić Petrović, Laća, and Kalicanin, 1972; Surana and Conen, 1972; Warter, Ruch, and Lehmann, 1973) and through propositi whose phenotype did not bear a causal relation with the inversion (Jacobs et al, 1968; Weitkamp et al, 1969; Crandall and Sparkes, 1970; Wahrman et al, 1972; Soudek et al, 1974). The study of the banding patterns of the inverted chromosomes and their recombinants allows for the precise identification of the length of the inverted segment. Consequently a better evaluation of the relation between the length of the inverted segment and the meiotic behaviour of the abnormal chromosome can be achieved.

We describe here a carrier of a pericentric inversion of chromosome 18 and her two offspring, both carriers of chromosome 18 recombinants.

Received 20 November 1975.

\section{Case report}

Propositus (Fig. 1). The second child was born to nonconsanguineous healthy parents, a 21-year-old mother and a 26-year-old father, in September 1971. The only sib was a mentally retarded girl with the multiple congenital anomalies which are described below. The mother had not had any spontaneous abortions. One of the mother's sisters was mentally retarded. The propositus was born after an uneventful pregnancy and delivery. Birthweight was $2840 \mathrm{~g}$ but the body length was not recorded. Evaluation at 18 months showed a hypotonic child with severe developmental retardation and multiple congenital anomalies. His length was 73 $\mathrm{cm}$ and head circumference was $41.2 \mathrm{~cm}$ (both much below the third centile). Other features included: brachycephaly, sparse, thin, and short hair, and evidence of previous midline scalp defect, which was ascertained because of a $1 \mathrm{~cm}$ scar in the vertex. There was pronounced hypoplasia of the mid-portion of the face, better noticed in profile. Consequently, the nasal bridge was flat, the forehead relatively prominent, and there was a forward projection of the inferior portion of the face. The supraorbital ridges were noticeably flat, and there were epicanthal folds in the inner canthi. Long and numerous eyelashes were observed. Hypertelorism was apparent. The philtrum was somewhat 


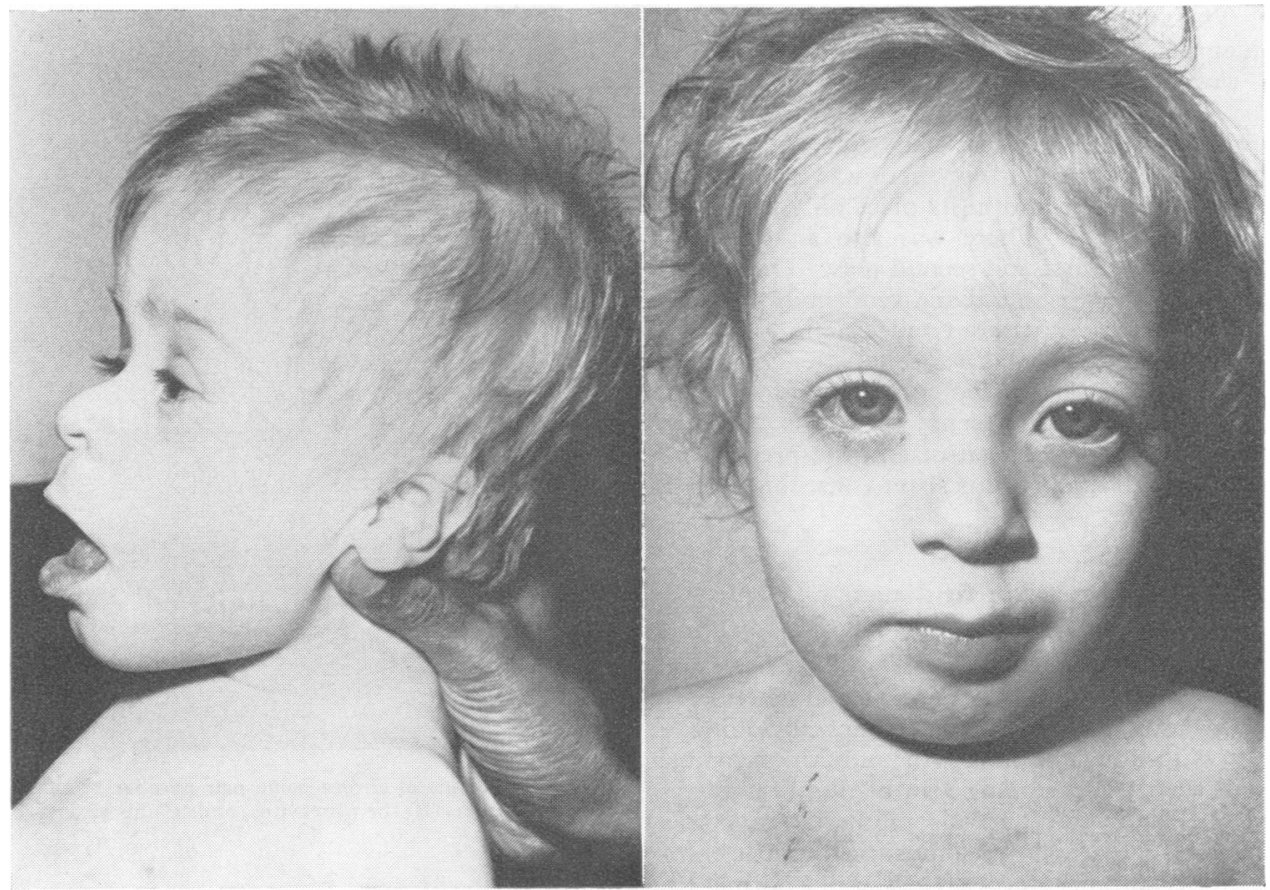

FIG. 1. Propositus at 18 months of age.

FIG. 2. The sister of the propositus at 3 years and 6 months.

elongated and its groove poorly defined. The mouth was carp-shaped with downward displacement of the lateral portions. The eight deciduous incisors were present in the mouth. The mandible could easily be displaced either actively or passively forward, leading to a transitory prognathism. The ears had a small tragus and an overfold of the upper helix. The only abnormal finding in the thorax was an increased distance between the nipples. There was a narrow pelvis, with limited hip abduction. The genitalia had a hypoplastic appearance: the scrotum was flat and smooth, testes were undescended, and the penis was very small and hidden in the suprapubic adipose tissue. A simian crease was present in both hands; all fingers except the first and second had a slight degree of camptodactyly. Swelling was noted in the dorsum of both feet. The bone age was
6 months (Greulich-Pyle) and an electroencephalogram showed asynchronous activity.

Sister of propositus (Fig. 2). The elder sister was born in February 1970. Normal delivery followed an uneventful pregnancy. The birthweight was $2150 \mathrm{~g}$. Examination at 3 years and 6 months showed a mentally retarded girl. Multiple haemangiomata were present on the nape at the neck, above the left elbow, on the lumbar region, and on the left thigh, just above the knee. Her height was $89 \mathrm{~cm}$ (below the third centile) and her head circumference was $48.3 \mathrm{~cm}$ (about the 50th centile). She had a protruding sagittal suture, flat supraorbital ridges, and an asymmetrical face. Ptosis and small palpebral fissures were noted. The ears had somewhat simplified helix and antihelix. Slight micrognathia was

TABLE

DERMATOGLYPHIC PATTERNS

\begin{tabular}{|c|c|c|c|c|c|c|c|c|c|c|}
\hline & I & II & $\begin{array}{l}\text { Digit } \\
\text { III }\end{array}$ & IV & $\mathrm{V}$ & TRC & $\begin{array}{l}a-b \\
\text { ridge } \\
\text { count }\end{array}$ & $\begin{array}{l}\text { atd } \\
\text { angle }\end{array}$ & Palmar formula & $\begin{array}{l}\text { Hallucal } \\
\text { Areas }\end{array}$ \\
\hline $\begin{array}{l}\text { Propositus } \\
\text { Right } \\
\text { Left }\end{array}$ & W & $\mathbf{U}$ & $\underset{\mathbf{W}}{\mathbf{W}}$ & $\underset{\mathbf{W}}{\mathbf{W}}$ & $\underset{\mathbf{W}}{\mathbf{W}}$ & 138 & 58 & $\begin{array}{l}34.5^{\circ} \\
44^{\circ}\end{array}$ & $\begin{array}{l}\text { 9(10).9.7(6). } 5^{\prime}-t-A^{r} \text {.O.O.L.O } \\
\text { 9.X.5"11-t - Lr.Lc/V.O.O.O }\end{array}$ & $\underset{\mathbb{W}}{\mathbf{L}^{\mathbf{d}}}$ \\
\hline $\begin{array}{l}\text { Sister } \\
\text { Right } \\
\text { Left }\end{array}$ & $\begin{array}{l}\text { A } \\
\mathbf{A}\end{array}$ & A & $\begin{array}{l}\mathbf{A} \\
\mathbf{A}\end{array}$ & $\begin{array}{l}\text { A } \\
\text { A }\end{array}$ & $\begin{array}{l}\text { A } \\
\text { A }\end{array}$ & 0 & 65 & $47.5^{\circ}$ & $\begin{array}{l}\text { 11.9.7.5" }-t^{\prime}-\text { O.O.O.L.O } \\
\text { 10.0.6.5' }-t^{\prime}-\text { O.V/O.O.O.O }\end{array}$ & $\begin{array}{l}\mathbf{L}^{d} \\
\mathbf{L}^{d}\end{array}$ \\
\hline
\end{tabular}


present. The anterior thoracic diameter was increased, with no identifiable cardiopathy or pneumopathy. The sternum was short. Hypoplastic labia majora were observed. Camptodactyly of the fifth digit was present on both hands. The feet were flat, with slightly prominent heels. On the right foot there was a severe hypoplasia of the third toe and in its place only a vestigial rudiment was noticed. There was also an abnormal diastasis between the first and second toes. On the left foot there was complete soft tissue syndactyly between the third and fourth toes, without nail fusion.

Dermatoglyphs. Dermatoglyphs are summarized in the Table. The high frequency of whorls $(7 / 10)$ on the digital areas in the propositus, and the presence of simple arches on all digits of his sister constitute the remarkable features.

\section{Cytogenetic findings}

After routine chromosome analysis on peripheral blood leucocytes the procedure of Caspersson, Lomakka, and Zech (1971) was employed to obtain Q-band patterns.

The propositus had 46 chromosomes including a number 18 , with a deleted long arm; only the proximal bright band typical of the long arm of number 18 was seen (Fig. $3 \mathrm{~B}$ and $4 \mathrm{~B}$ ). In his mother's karyotype, a number 18 was replaced by an almost metacentric chromosome. This chromosome was the size of a normal 18; one arm showed the bright proximal band and the other, the bright distal band of the long arm of number 18 (Fig. $3 \mathrm{~A}$ and $4 \mathrm{~A}$ ). The sister of the propositus had 46 chromosomes including a submetacentric longer than a number 16; the fluorescence patterns of its long arm were similar to those on the long arm of a normal 18; on its short arm, a bright fluorescent band corresponding to the bright distal band of the long arm of number 18 was seen (Fig. $3 \mathrm{C}$ and $4 \mathrm{C}$ ).

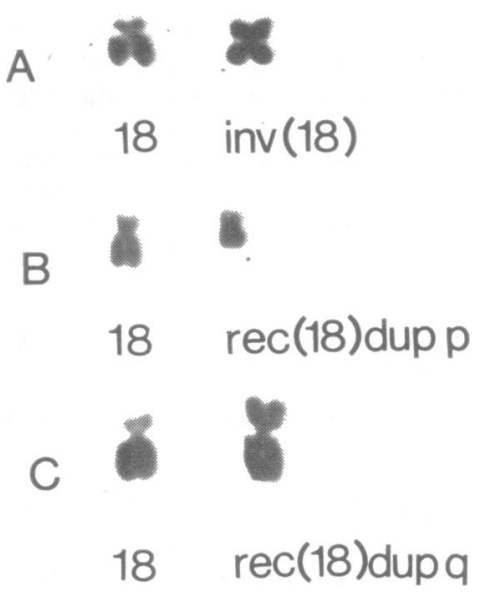

FIG. 3. Chromosome pair number 18 of (A) the propositus' mother $B)$ the propositus, and (C) his sister.

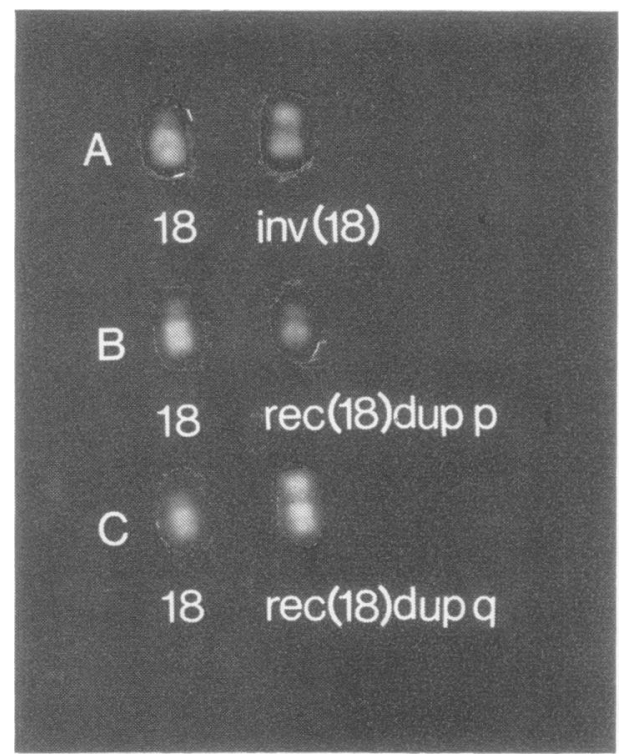

Fig. 4. Q-bands of chromosome pair number 18 of (A) the propositus' mother, (B) the propositus, and (C) his sister.

The metacentric chromosome seen in the mother of the propositus was thought to result from a pericentric inversion of chromosome 18. This inversion probably took place in one of her parents during gamete formation. The breakpoints were probably located on band 1 of region 1 of the short arm and on band 1 of region 2 of the long arm (Fig. 5). Her chromosome constitution may be written: $46, \mathrm{XX}$,inv(18)(p11q21), or $46, \mathrm{XX}$,inv $(18)($ pter $\rightarrow$ p11 $:: q 21 \rightarrow$ p11 $:: q 21 \rightarrow$ qter $)$. The inverted segment represents about $60 \%$ of the total length of chromosome 18.

The abnormal chromosomes found in the propositus and his sister may be interpreted as recombinants which resulted from a chiasma occurring within the inverted segment (Fig. 5). The propositus received a number 18 with a deletion of the distal one-third of the long arm and a duplication of the terminal segment of the short arm. The propositus' sister received a number 18 with a duplication of one-third of the long arm and deletion of the terminal segment of the short arm. Thus the propositus is monosomic for the distal one-third of the long arm and trisomic for the terminal segment of the short arm: $46, X Y,-18,+\operatorname{rec}(18)$ dup $p$, inv $(18)$, (pter $\rightarrow q 21::(p 11 \rightarrow$ pter) mat. His sister is trisomic for the distal onethird of the long arm and monosomic for the terminal segment of the short arm of chromosome 18: 46, $\mathrm{XX}$, $-18,+\operatorname{rec}(18)$ dup $p$, inv(18), (qter $\rightarrow$ q21 : :p1 $1 \rightarrow q$ ter) mat. The phenotypic features of the propositus are consistent with the diagnosis of $18 \mathrm{q}$ - syndrome. His sister presents clinical signs compatible with a partial 18 trisomy. 
ORIGINAL

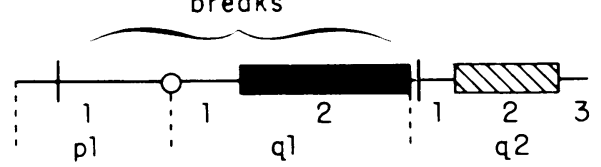

I NVERTED $n^{0} \cdot 18$

$\operatorname{inv}(18)(p 11 q 21)$

(PROPOSITUS' MOTHER)
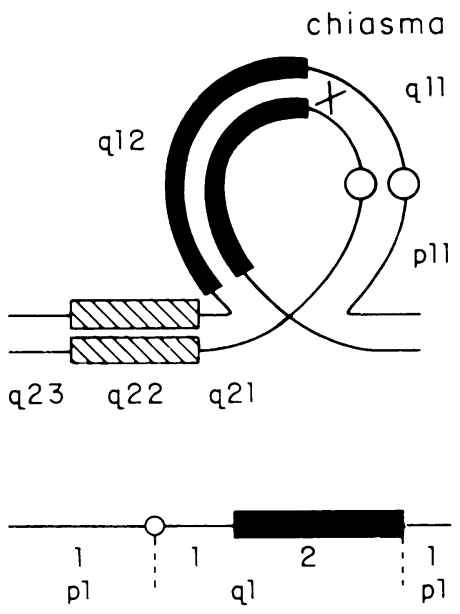

$\operatorname{rec}(18)$ dup $p, \operatorname{inv}(18)(p 11$ q21)

(PROPOSITUS)

\section{RECOMBINANTS}

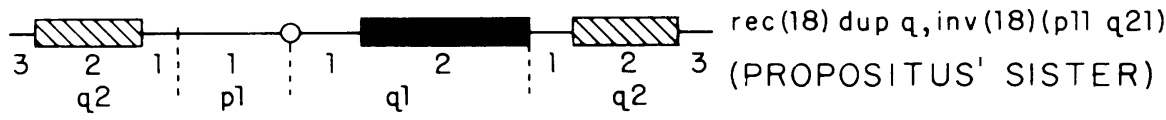

FIG. 5. Diagram showing the recombinant formation following a chiasma within the inverted segment of the maternal chromosome 18 .

The propositus' father, maternal grandparents, and two maternal aunts, one of whom was mentally retarded, showed normal karyotypes.

\section{Discussion}

The length of the inverted segment is a factor to be considered when evaluating the meiotic behaviour of inverted chromosomes. This has been recognized since the first studies on the meiotic pairing in heterozygotes for inversions were performed (McClintock, 1931; 1933). Sjödin (1971), studying induced inversions in Vicia faba, pointed out the importance of considering the relative length of the inverted segment.

In humans, chromosomally deficient and dupli- cated individuals born to normal parents one of whom is heterozygous for a pericentric inversion of an autosome have been described (Wilson et al, 1970; Parrington and Edwards, 1971; Faed et al, 1972; Hauksdöttir et al, 1972; Morić-Petrović et al, 1972; Surana and Conen, 1972; Warter et al, 1973; Jacobs, Melville, and Ratcliffe, 1974). Reduced fertility and an increase in neonatal death in the offspring of heterozygous inversion carriers have been reported in some of these families (Parrington and Edwards, 1971; Faed et al, 1972; Hauksdöttir et al, 1972). In only one instance have both possible recombinants from an inverted chromosome been described in the same sibship (Warter et al, 1973): an inverted number 5 chromosome was 
present in the normal carrier father of two girls affected by the 'cri-du-chat' syndrome and its counterpart, respectively. An inversion of chromosome 18 with breakpoints sited in the same regions as in the one here reported was described by Jacobs et al (1974): the patient inherited from her mother both the original inverted chromosome and the recombinant, being trisomic for much of chromosome 18 and tetrasomic for a part of its short arm. The banding patterns and/or the morphology of the inverted and recombinant chromosomes allowed in each of the above cases the estimation of the inverted segment which ranged from $50 \%$ to $80 \%$ of the total chromosome length.

Inversions have also been reported in propositi whose phenotypic features were not causally related to the presence of the inversion and in their normal relatives. An increase of fetal losses or neonatal deaths was not observed in these families (Jacobs et al, 1968; Weitkamp et al, 1969; Crandall and Sparkes, 1970; Wahrman et al, 1972; Soudek et al, 1974). In each such case the probable position of the breakpoints assigns to the inverted segment a probable length of not more than $50 \%$ of the total chromosome length. Thus, at meiotic synapsis, the relatively short inverted segment probably would lead to nonhomologous pairing or asynapsis, preventing crossing over from occurring. These inversions could, therefore, be maintained in a polymorphic state in the population. This, at least, seems to be the case with those inversions involving the pericentromeric segment of chromosomes number 3 (Soudek et al, 1974), and number 9 (Jacobs et al, 1974).

In the present report, the mother of the propositus carried an inversion of a relatively long segment (about $60 \%$ of the total chromosome length). The probability of recombinant formation following the occurrence of a chiasma within the inverted segment appears high. The carrier of the inversion is, therefore, at high risk for unbalanced progeny.

The authors express their acknowledgment to $\mathrm{Dr} \mathrm{O}$. Frota Pessoa and Dr Lytt I. Gardner for their critical reading of the manuscript, and to Ms Gale Barg, for helpful suggestions.
This work was partly supported by The Multinational Genetics Program of the Organization of the American States, the Conselho Nacional de Pesquisas and the Fundaçã de Amparo à Pesquisa do Estado de São Paulo.

\section{REFERENCES}

Caspersson, T., Lomakka, G., and Zech, L. (1971). The 24 fluorescence patterns of the human metaphase chromosomes-distinguishing characters and variability. Hereditas, 67, 89-102.

Crandall, B. F. and Sparkes, R. S. (1970). Pericentric inversion of a number 15 chromosome in nine members of one family. Cytogenetics, 9, 307-316.

Faed, M. J. W., Marrian, V. J., Robertson, J., Robson, E. B., and Cook, P. J. L. (1972). Inherited pericentric inversion of chromosome 5: a family with history of neonatal death and a case of the 'cri-du-chat' syndrome. Cytogenetics, 11, 400-411.

Hauksdöttir, H., Halldórsson, S., Jensson, O., Mikkelsen, M., and McDermott, A. (1972). Pericentric inversion of chromosome No. 13 in a large family leading to duplication deficiency causing congenital malformations in three individuals. Fournal of Medical Genetics, 9, 413-421.

Jacobs, P. A., Cruickshank, G., Faed, M. J. W., Frackiewicz, A., Robson, E. B., Harris, H., and Sutherland, I. (1968). Pericentric inversion of a group C autosome: a study of three families. Annals of Human Genetics, 31, 219-230.

Jacobs, P. A., Melville, M., and Ratcliffe, S. (1974). A cytogenetic survey of 11,680 newborn infants. Annals of Human Genetics, 37, 359-376.

McClintock, B. (1931 ; 1933) apud John, B. and Lewis, K. R. (1965) The meiotic system, Protoplasmatologia: Handbuch der Protoplasmaforschung, 6, F/1, p. 67.

Morić-Petrović, S., Laća, Z., and Kalicanin, P. (1972). Down's syndrome with an atypical G/G translocation derived from familial pericentric inversion in one chromosome of the G-group. Fournal of Medical Genetics, 9, 478-482.

Parrington, J. M. and Edwards, J. H. (1971). Patau's syndrome with $D_{1}$ duplication deficiency derived from a maternal $D$ group pericentric inversion. Annals of Human Genetics, 35, 35-45.

Sjödin, J. (1971). Induced paracentric and pericentric inversions in Vicia faba L. Heriditas, 67, 39-54.

Soudek, D., O'Shaughnessy, S., Laraya, P., and McCreary, B. D. (1974). Pericentric inversion of 'fluorescent' segment in chromosome No. 3. Humangenetik, 22, 343-346.

Surana, R. B. and Conen, P. E. (1972). Inherited pericentric inversion of a group D (13-15) chromosome. Fournal of Medical Genetics, 9, 105-110.

Wahrman, J., Atidia, J., Goitein, R., and Cohen, T. (1972). Pericentric inversion of chromosome 9 in two families. Cytogenetics, 11, 132-144.

Warter, S., Ruch, J. V., and Lehmann, M. (1973). Karyotype with chromosomal abnormality with various inherited defects in the offspring (recombination aneusomy). Humangenetik, 20, 355-359.

Weitkamp, L. R., Janzen, M. K., Guttormsen, S. A., and Gershowitz, H. (1969). Inherited pericentric inversion of chromosome number two: a linkage study. Annals of Human Genetics, 33, 53-59.

Wilson, M. G., Towner, J. W., Coffin, G. S., and Forsman, I. (1970). Inherited pericentric inversion of chromosome No. 4. American fournal of Human Genetics, 22, 679-690. 